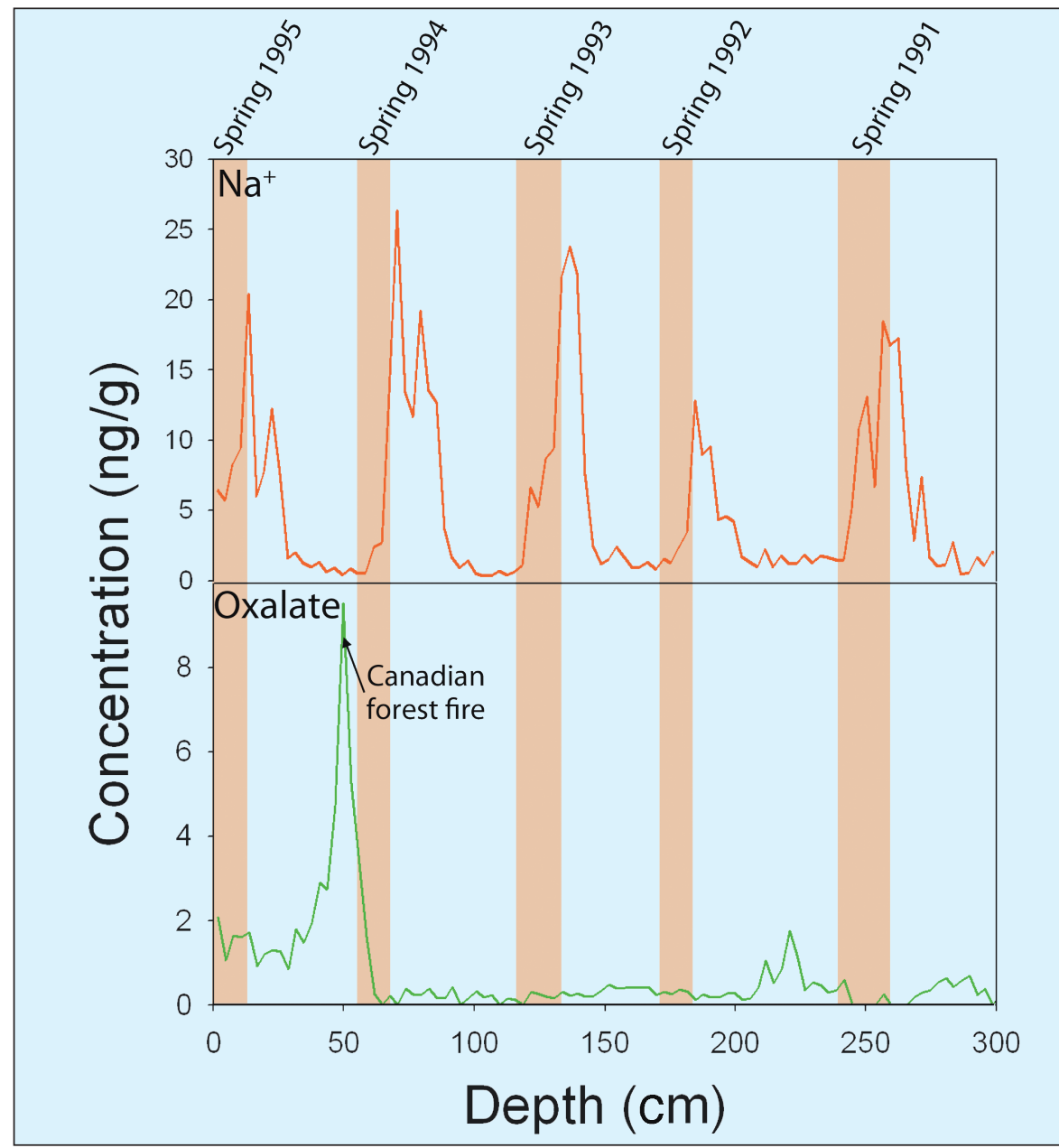

Figure 2: Changes in $\mathrm{Na}^{+}$(orange) and oxalate concentration (green; . $^{-1} \mathrm{~g}^{-1}$ ) averaged from 68 central Greenland snow-pit samples, from the surface (June 1995) to $2.7 \mathrm{~m}$ (1991). Peaks in $\mathrm{Na}^{+}$are associated with boreal winters as increased cyclogenesis in the North Atlantic deposits greater concentrations of sea salts on the Greenland Ice Sheet. Orange bars indicate the position of spring snow accumulation. Figure modified from Barbanteet al., 2003.

\section{Conclusion}

Glaciers and ice sheets incorporate tracers of biomass burning into their ice layers resulting in a multitude of paleoenvironmental data within a single matrix. Molecular markers in ice cores provide insight into past fire occurrence, the type of material burned and the impacts of human activity. The global array of ice cores supplies high-resolution Quaternary proxy records that encompass six continents. The study of molecular markers of past fires in ice cores is still in its infancy and future work should also incorporate studies into the stability, durability and degradation mechanisms that may affect molecular markers under different conditions. Even with these caveats, the investigation of organic atmospheric tracers is expanding the limits of proxy information gleaned from ice cores and creates the possibility to couple fire activity, climate oscillations and human activity.

\section{Data}

The data from Figure 1 is available from Roberta Zangrandp (Rozangra@unive.it). Data presented in Figure 2 is available from Carlo Barbante (Barbante@unive.it).

\section{Acknowledgements}

This study is a contribution to the Marie-Curie Incoming International Fellowship Project (PIIFGA-2009-236961 - PaleoFire) and the Past4Future program funded by the European Commission.

\section{References}

Barbante, C., Boutron, C., Morel, C., Ferrari, C., Jaffrezo, J.G., Cozzi, G., Gaspari, V. and Cescon, P., 2003: Seasonal variations of heavy metals in central Greenland snow deposited from 1991 to 1995 Journal of Environmental Monitoring, 5: 328-335.

Conedera, M., Tinner, W., Neff, C., Meurer, M. and Dickens, A., 2009 Reconstructing past fire regimes: methods, applications, and relevance to fire management and conservation, Quaternary Science Reviews, 28: 555-576.

Gabrieli, J., et al., 2010: Post 17th-Century Changes of European PAH Emissions Recorded in High-Altitude Alpine Snow and Ice, Environmental Science and Technology, 44: 3260-3266.

Gambaro, A., Zangrando, R., Gabrielli, P., Barbante, C. and Cescon, P., 2008: Direct determination of levoglucosan at the picogram per milliliter level in Antarctic ice by high-performance liquid chromatography/electrospray ionization triple quadrupole mass spectrometry, Analytical Chemistry, 80: 1659-1699.

Simoneit, B.R., 2002: Biomass burning - A review of organic tracers for smoke from incomplete combustion, Applied Geochemisty, 17 129-162.

For full references please consult:

http://www.pages-igbp.org/products/newsletters/ref2010_2.html

\title{
Global patterns of biomass burning during the last glacial period
}

\section{Anne-Laure Daniau}

School of Geographical Sciences, University of Bristol, UK; al.daniau@bristol.ac.uk

\section{Sedimentary charcoal records covering the last glacial period provide information on the response of global biomass burning to rapid climate changes, such as those occurring during Dansgaard-Oeschger cycles.}

The Global Palaeofire Working Group (http://www.gpwg.org/) has updated a database of over 700 individual sedimentary charcoal records worldwide (GCD_V2: Daniau et al., in prep). This database provides a powerful tool for studying changes of biomass burning at global and regional scale (Power et al., 2008; Power et al., 2010). A focused study of fire records covering the last glacial period $(73.5-14.7 \mathrm{ka})$ allows examination of the response of biomass burning to the rapid climate changes (within 10-200 years) of large magnitude that occurred during Dansgaard-Oeschger (D-O) cycles (Steffensen et al., 2008). D-O cycles are characterized in Greenland ice-core records by a marked warming followed by a cooling. Herein, D-O warming events refer to the initial rapid warming (Sánchez-Goñi and Harrison, in press), Greenland Interstadials (Gl) correspond with the D-O warm phase followed by the initial slow phase of cooling, D-O cooling events refer to the precipitous cooling at the end of Gl, and Greenland Stadials (GS) correspond with the final cool phase.

\section{Methodology}

Sixty-seven sites (11 marine and 56 terrestrial; Fig. 1) that have records for some part of the last glacial period were extracted from the database and used to analyze changes in global biomass burning (Daniau et al., in press). These records were developed using a broad range of quantification methods and units. For the majority, charcoal counts were converted to charcoal concentration (number of particles $\mathrm{cm}^{-3}$ or per $\mathrm{g}$ of sediment), charcoal influx (number of particles $\mathrm{cm}^{-2} \mathrm{a}^{-1}$ ) or charcoal 
area measurements made directly on pollen slides or using image analysis. A few records also used chemical assay, such as total organic fraction and black carbon concentration, or were expressed as Charcoal/Pollen ratio and percentage dry weight. The data were therefore standardized to facilitate comparisons between sites and through time. Original charcoal data (abundance or concentration) were transformed and rescaled to obtain a common mean and variance for all sites, and detrended to remove orbital timescale variability. Superposed Epoch Analysis (SEA) was performed on the detrended charcoal data to examine the pattern of fire around the time of key events, aligning the charcoal deviations on the ages of the D-O warming and D-O cooling events (Fig. 2). When the SEA summary curves fall outside a confidence band determined by Monte Carlo methods, a significant or systematic response of the variable to some externally determined event is inferred.

\section{Fire and temperature}

Figure 2 illustrates SEAs for the NGRIP oxygen-isotope data and the global composite-curve of charcoal data. These illustrate the nature of the abrupt temperature changes and the response of global biomass burning to the abrupt warming at the beginning of the $\mathrm{Gl}$ and the most rapid interval of cooling that delimits the beginning of GS. A general increase in charcoal levels during warming (Fig. 2a, b) and a decrease in charcoal levels during cooling (Fig. 2c, d) suggest a strong correlation between biomass burning and temperature. Biomass burning increases rapidly during D-O warming events and reaches a peak at nearly the same time as temperature. In contrast, biomass burning decreases significantly at the onset of the GS and then returns to "background" levels, even though temperatures remain low (Figs. 2c, d). The response of biomass burning to the warming events is not the simple inverse of the response to cooling, suggesting a nonlinear relationship between biomass burning and climate. The association between rapid warming and increases in biomass burning seen during the glacial period has also been observed during the last deglaciation at the termination of the Younger Dryas chronozone (Marlon et al., 2009).

\section{Fire regime and fuel}

Changes in charcoal concentration have been described from two marine records off the European margin and interpreted as changes in biomass burning caused by variations in fuel availability during D-O

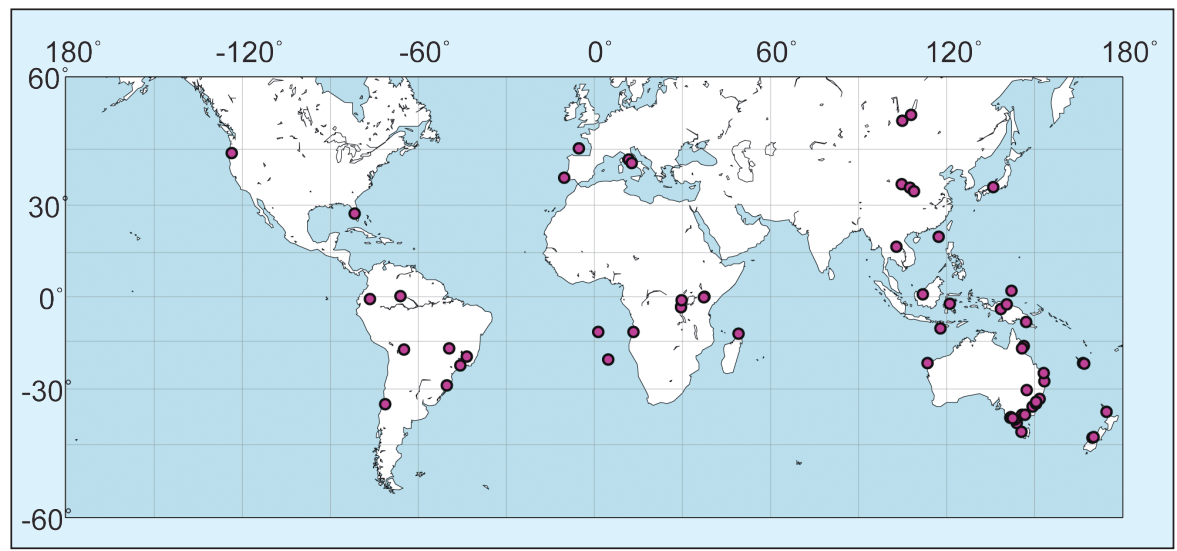

Figure 1: Location of marine and terrestrial sites with charcoal records covering all or part of the last glacial period. Figure modified from Daniau et al., in press.

cycles (Daniau et al., 2007; Daniau et al., 2009). Recent syntheses of the glacial vegetation history of Europe, Japan and adjacent parts of the Asian mainland, North America and the tropical regions of South America and Africa (Fletcher et al., in press; Takahara et al., in press; Jiménez-Moreno et al., in press; Hessler et al., in press) suggest that these rapid climate changes had an impact on vegetation globally. D-O warming events are generally accompanied by shifts from open vegetation to forest or increases in tree abundance. The similarity of variations in global levels of fire and regional vegetation patterns suggest that climate-driven changes in vegetation and biomass productivity (fuel)

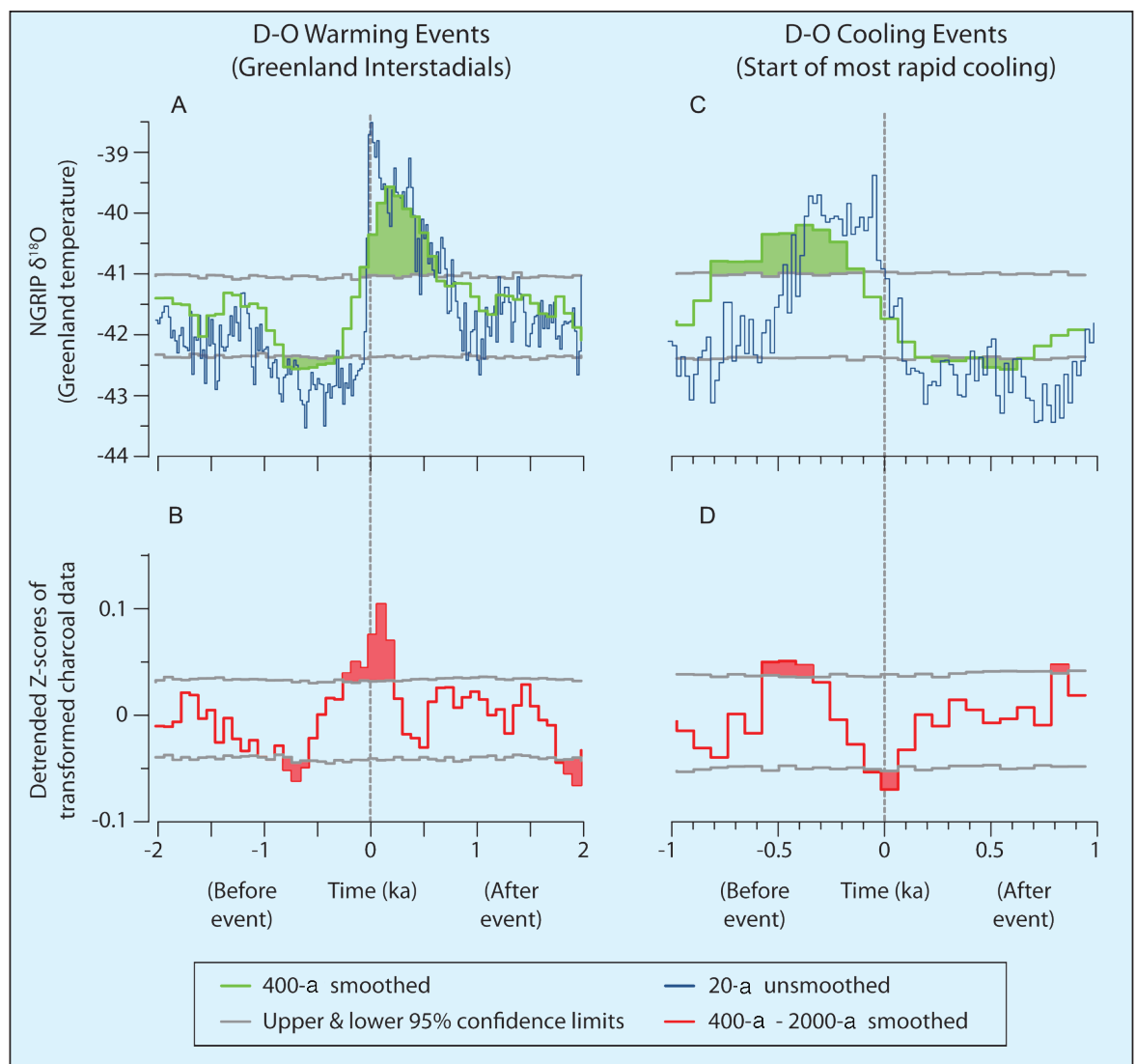

Figure 2: Superposed Epoch Analysis (SEA) composites illustrating changes in biomass burning associated with $D-O$ warming events $(\boldsymbol{A}$ and $\boldsymbol{B})$ and D-O cooling events (C and $\boldsymbol{D})$. The NGRIP $\delta^{18} O$ SEA composite record for the $D$-O cycles is shown for comparison. The NGRIP oxygen-isotope data (Wolff et al., in press) were integrated over 20-a-wide bins (the resolution of the data; blue lines), and over 80-a-wide bins (same resolution as the charcoal data, green lines), for comparison with the SEA of the charcoal data. The confidence intervals are given by a Monte-Carlo simulation using the timing of the $20 \mathrm{D}-\mathrm{O}$ warming events and $19 \mathrm{D}-\mathrm{O}$ cooling events. Figure modified from Daniau et al., in press. 
explore changes in global fire regimes during a period of high millennial-scale climate variability. Biomass burning at the global scale apparently responded rapidly to variations in temperature, as recorded in the Greenland ice core. Increases in biomass burning were synchronous with warming, whereas cooling was accompanied by decreases in burning followed by a return of fire to previous levels. Changes in vegetation productivity and fuel availability may explain the inferred variations in biomass burning during D-O cycles.

Additional paleofire records are still needed to derive statistically robust results at a regional scale and to better examine fire and climate interactions. Global biomass burning responds to past temperature variations, but we also seek to explore the importance of seasonality of temperature and precipitation on fire, which play a role in shaping the vegeta- tion (type of biomes, abundance of fuel) and the flammability of fuel. We intend to extend the database by adding worldwide long and high-resolution marine and terrestrial charcoal records, in particular from poorly documented areas of North America, Africa and Eurasia. There is a great potential for long marine records to document regional fire activity where terrestrial records are not available. Characterization of the role of temperature and precipitation on fire would also benefit from the close comparison between fire and well-documented high-resolution changes in vegetation during $\mathrm{D}-\mathrm{O}$ climate shifts, for example, in Europe where these rapid changes led to an alternation between open and forested biomes.

\section{Data}

The data presented herein will be available in the version 2 of the Global Charcoal Database when it is released (see http://www.gpwg.org/).

\section{Acknowledgements}

I thank P.J. Bartlein, M.F. Sánchez-Goñi, W. Tinner and C. Whitlock for helpful comments and English revision, which greatly improved the manuscript.

\section{References}

Daniau, A.-L., Harrison, S.P. and Bartlein, P.J., in press: Fire regimes during the Last Glacial, Quaternary Science Reviews, doi:10.1016/j. quascirev.2009.11.008.

Marlon, J.R., et al., 2009. Wildfire responses to abrupt climate change in North America, Proceedings of the National Academy of Sciences, 106(8): 2519-2524 doi: 10.1073/ pnas.0808212106.

Power, M.J., Marlon, J.R., Bartlein, P.J. and Harrison, S.P., 2010: Fire History and the Global Charcoal Database: a new tool for hypothesis testing and data exploration, Palaeogeography, Palaeoclimatology, Palaeoecology, 291(1-2): 52-59.

Sánchez-Goñi, M.F. and Harrison, S.P., in press: Millennial-scale climate variability and vegetation changes during the last glacial: concepts and terminology, Quaternary Science Reviews, doi:10.1016/j.quascirev.2009.11.014

Wolff, E.W., Chappellaz, J., Blunier, T., Rasmussen, S.0. and Svensson, A., in press: Millennial-scale variability during the last glacial: The ice core record, Quaternary Science Reviews, doi:10.1016/j. quascirev.2009.10.013

\title{
A fire paradox in ecosystems around the Mediterranean
}

\author{
Boris VAnNière ${ }^{1}$, D. Colombaroli ${ }^{2}$ and N. Roberts ${ }^{3}$ \\ ${ }^{1}$ CNRS, Chrono-Environment Laboratory, University of Franche-Comté, Besançon, France; boris.vanniere@univ-fcomte.fr \\ Institute of Plant Sciences and Oeschger Center for Climate Change Research, University of Bern, Switzerland; ${ }^{3}$ School of Geography, Earth and \\ Environmental Sciences, University of Plymouth, UK
}

\section{Multi-proxy sedimentary charcoal records show that, despite evidence of early human-induced fire, the regional-scale switch from climate-regulated to human-dominated biomass burning occurred only between 4 and $2 \mathrm{ka}$ in the Mediterranean region, coinciding with a late-Holocene expansion of fire-adapted ecosystems.}

Wildfires in Mediterranean countries are a regular agent of disturbance for ecosystems and are generally attributed to a combination of extreme summer drought, strong winds and heat-waves along with accidental-or sometimes deliberateignition by human hands (e.g., Pausas, 2004). While these factors are certainly among the contemporary causes, the ultimate causes operating over multi-decadal and longer timescales are far from fully understood. What does the past tell us about the respective roles of climate and human actions in determining long-term Mediterranean fire regimes? Compared with other Mediterranean-like ecosystems in the world (e.g., chaparral in California), the Mediterranean basin has experienced a long history of human occupation, with human fire use recorded as far back as 0.8 Ma in eastern Mediterranean regions (Alperson-Afil, 2008). The spread of agriculture in the Mediterranean started more than $11 \mathrm{ka}$ ago and Neolithic populations were present in the whole region from $\mathrm{ca} .7 \mathrm{cal}$ ka BP (Bocquet-Appel et al., 2009). Thus, disentangling climate and human causes is often difficult in the Mediterranean area because these drivers may operate syner- gistically. Well-dated sedimentary archives help us to understand when fire regimes switched from being climate- to humandominated across the region. In recent years, multi-proxy studies and regional- to global-reconstructions of biomass burning have greatly improved our knowledge about fire-climate-human interactions in the past. Here we discuss how Holocene fire-ecosystem-climate-human linkages can be inferred from paleoecological studies in the Mediterranean area.

\section{Fire-vegetation-climate relationships}

Recent charcoal-based studies from welldated lake sediments show that fire frequency in the Mediterranean region varied significantly throughout the last 11.6 ka (Holocene). Fire has played a contrasting role in the history of circum-Mediterranean landscape ecosystems; sometimes positive (e.g., increasing biodiversity) and at other times negatively affecting ecosystems (e.g., disrupting forest stands; Vannière et al., 2008). For instance, paleoecological records show that late-summer grassland burning delayed the early postglacial re-advance of woodland across in- terior areas of southwest Asia by up to $3 \mathrm{ka}$ (Turner et al., 2010). In Sicily (Gorgo Basso; Fig. 1A), higher fire frequency before $8 \mathrm{cal}$ ka BP probably restricted broadleaved evergreen stands (Tinner et al., 2009). Similarly, and in contrast to commonly held ecological assumptions, high-resolution pollen and charcoal time series from different sites in the central Mediterranean show that evergreen forest ecosystems (e.g., with Quercus ilex) were disadvantaged or even irretrievably destroyed by fire (Colombaroli et al., 2009; Fig. 1B). Thus, increasing drought and/or fire activity in the future could strongly endanger relict stands of $Q$. ilex in southern parts of the Mediterranean region and favor the expansion of drought-adapted maquis vegetation.

Multi-proxy approaches have provided additional insights. For example, Turner et al. (2008) compared proxies for fire activity (microscopic charcoal data, particles $<180 \mu \mathrm{m}$ in diameter), land use and vegetation (pollen data) and climate (oxygen isotope data) from Eski Acıgöl crater record (Central Turkey; Fig. 2A). Landscape burning coincided with periods of wetter climate at centennial- to millennial- 